\title{
Article
}

\section{Lean in a cold físcal climate: The public sector in an age of reduced resources}

Martin, Douglas

Available at http://clok.uclan.ac.uk/20227/

Martin, Douglas ORCID: 0000-0003-4056-5869 (2017) Lean in a cold fiscal climate: The public sector in an age of reduced resources. Public Money \& Management . pp. 29-36. ISSN 0954-0962

It is advisable to refer to the publisher's version if you intend to cite from the work. http://dx.doi.org/10.1080/09540962.2018.1389501

For more information about UCLan's research in this area go to

http://www.uclan.ac.uk/researchgroups/ and search for < name of research Group>.

For information about Research generally at UCLan please go to http://www.uclan.ac.uk/research/

All outputs in CLoK are protected by Intellectual Property Rights law, including Copyright law. Copyright, IPR and Moral Rights for the works on this site are retained by the individual authors and/or other copyright owners. Terms and conditions for use of this material are defined in the policies page.

\section{CLoK}

Central Lancashire online Knowledge www.clok.uclan.ac.uk

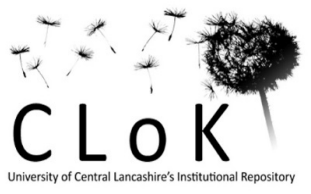




\title{
Lean in a cold fiscal climate: the public sector in an age of reduced resources
}

Douglas Martin is a lecturer in Human Resource Management at the University of Central Lancashire

\begin{abstract}
Reflecting on recent public sector reform, this article examines the use of lean during a period of financial austerity. The article outlines several challenges for public sector organisations as they manage performance targets, and engage in service re-design. The author challenges the current use of lean working arguing for a reevaluation of the traditional public sector model of work and for a collective approach to co-production of service redesign.
\end{abstract}

Lean; public sector; fiscal climate; co-production; performance targets

Reflecting on public sector reform in the wake of the 2008 financial crash, Christopher Hood (2013) highlighted the issues facing government. The state is under constant political pressure from the electorate to restructure public services as the state strives to do 'less with less'. Hood sketches out three scenarios that the state may follow to address the twin demands of fiscal pressure and an electorate seeking the maintenance of public services. First, the state may increasingly use performance targets based on productivity rather than administrative measures. Secondly, the state may opt for extensive service redesign focused on co-production and cost containment. Finally, Hood argues that the state may opt to use the 'East of Suez' approach. Analogous to Britain's withdrawal from imperial interests in the post-war period, the state would effectively withdraw involvement from areas previously within the ambit of government responsibility.

The 'cold fiscal climate' of the post-2008 crash has already changed the shape of public services. The current government agenda is based on extensive public sector cost reduction: the fiscal climate has become increasingly glacial with little likelihood of change in the foreseeable future. Public sector management has made extensive use of business improvement methods to effect cost reduction in the state sector. With its emphasis on the use of the workforce as the means to improve organisational efficiency, lean has been a predominant approach within the current public sector. It is an opportune moment to consider the future direction of lean in this increasingly cold fiscal climate.

\section{Lean and the cold fiscal climate}

Lean has been widely used across the state sector, most noticeably in such areas as the National Health Service and the Civil Service (e.g. Waring and Bishop, 2010; Radnor and Johnston, 2013). On one level, the benefits of lean could be evaluated from the significant savings accrued through lean working (National Audit Office, 2011), yet caution needs to be exercised. The savings relative to the cost of implementing lean may be minimal (Moraros et al., 2016). Moreover, despite assertions of lean's potential to generate greater organisational efficiency (Esain et al., 2008; Fillingham, 2007), its implementation into the public sector has been problematic. State sector management has uncritically transferred lean from its origins in manufacturing or based its implementation on the business rationale of the private sector. Lean is used to treat the 'customer' as a process to be managed rather than identify the most effective means to add value to public services (Radnor and Johnston, 2013). More radically, Carter et al. (2011b) contend that the ideology of lean is based on increasing management control of the labour process which has led to the intensification of work for state employees.

One of the central issues is to what extent managers can operate lean systems in tandem with a tight fiscal regime without succumbing to its coercive forms. For some, the solution to its flawed implementation is not to abandon lean, but to address any deficiencies as something that can be rectified with the right levers. Rather than view lean only in operational terms where the focus is principally cost reduction, one approach is to change the focus of lean. Instead of a focus on lean as a technical solution to resolve an efficiency issue, Osborne et al. (2012) argue that forms of organisational restructuring need to place the recipient of state services at the centre of the 
process. Rather than use a rationale for lean working taken from manufacturing where the techniques of lean drive the direction of the organisation, they argue for the adoption of a public service dominant model. This would not only allow lean to be applied within a service, rather than a manufacturing, environment, but it also would recognise that what is distinct about the public sector is that it provides public goods within society rather than public products.

The public service dominant view propounded by Osborne et al., (2012) emphasises the importance of the views and expectations of citizens in the delivery of public services. In effect, the service provider and the service user become closer through a form of co-production. Work processes thus need to be created with the aim of the user in mind (Radnor and Osbourne, 2012). However, co-production also needs to reflect the significant differences between provider-user interactions that are intermittent and transactional and those that are sophisticated and continuous (Needham, 2007; Bovaird, 2007). Public sector co-production connotes the voluntary contribution of the service user: co-production reflects a deliberate decision to engage with the service delivery process (Brandsen and Honingh, 2015). Nonetheless, the provider-user relationship cannot be the sole determinant of service delivery. Distinctively in the public sector, customer satisfaction cannot be the only factor shaping services: the public sector has multiple stakeholders whose interests may difficult to reconcile (Osborne et al., 2012). However, other than a notional acknowledgement of the need to involve the public in the development of state services, it would appear that the public is largely excluded from co-producing a specifically 'lean' service.

What then for lean in a cold fiscal climate? Lean may provide further potential for financial savings, but the lean approach may be at the cost of greater work intensification and poorer job quality. If lean continues to be the business improvement method of choice, certain factors will influence its implementation. The agency of individual senior managers is unlikely to be the defining determinant for the adoption of lean. Beginning with the Gershon report in 2004, the state has had significant influence on the choice of approach and will continue to exert influence as financial pressures continue. Hood's (2013) theoretical framework provides a basis for examining the future direction of lean. The main focus will be on the first two of Hood's propositions: the shift to productivity targets and service redesign. The minimal state envisaged by the East of Suez scenario where jobs disappear in their entirety and nothing is left to 'lean' merits more extensive treatment than can be provided here.

The first of Hood's scenarios, a switch in emphasis from targets based on administrative measures to ones based on productivity represents the development of an existing model. The emphasis on performance targets has been a significant feature of public administration since the Blair government (Bovaird and Russell, 2007), but the switch from administrative to productivity targets is likely to further change the ways in which the workforce delivers public services. Productivity targets relate to the amount of effort expended relative to the resource available. Administrative targets in this context relate primarily to the quality of the work undertaken. Although there is often a rather simplistic presumption that the two types of targets are mutually supportive and compatible, the relationship between productivity and administrative targets is more complex. The underlying assumption of the maxim "working smarter not harder", in effect that effective business improvement methods equate to more efficient working, is not wholly sustainable in practice. Furthermore, the types of target chosen by management reflect political drivers (Diefenbach, 2009). Within the current climate, these are premised on cost containment. At a workplace level, productivity based targets are currently often used to the exclusion of any activity that does not attract a target (Carter et al., 2011a, Bach and Kessler, 2012). The types of routine or standardised work delivered by much of the Civil Service, where there is minimal need for service-user interaction, lends itself to a greater reliance on productivity targets. Work where the service-provider to service-user interaction is personal and interactive currently needs a greater emphasis on administrative targets that seek to measure service quality. Although the NHS doctor-patient interaction is undoubtedly still subject to performance targets based on numbers of patients seen, user ratings of the quality of the consultation remain key indicators of performance. However, the likelihood is that the state may increasingly seek to promote productivity targets over administrative targets - quality may become a 'given', something that is expected, leaving productivity as the defining measure of performance.

This potential shift in the direction of performance targets may have a significant impact on the future implementation of lean. The question arises to what extent lean implementation in central government, where 
interactions are often transactional, is a harbinger of things to come, or whether the lean model used in front facing organisations where quality targets are preeminent is the likely direction.

For some, lean presents the potential to use the public service dominant model of service delivery to create a more efficient and responsive public service with state employees and public working together to coproduce the services required. This focus on the service user is often lacking (Radnor and Osborne, 2013): therein lies the problem for lean in central government where interactions between users and producers are often intermittent and transactional. Any further switch to productivity targets would further reduce the potential for lean to operate in the ways its advocates believe it should. The inextricable link between performance targets and regulation of the workforce is most obviously manifested by how state management use productivity targets. However, retaining administrative targets may also be problematic in the current environment. Two issues emerge here. The first issue relates to the link between productivity and service quality. An assumption of lean systems is that improving service quality is central to increasing effective productivity. Ergo, the pursuit of productivity targets at the expense of quality is one of the reasons why lean implementation has been unsuccessful. The emphasis should be focused on service producers and users working together in a form of co-production to develop quality systems out of which greater productivity will arise. Focusing on getting quality right becomes in effect the means to achieving greater productivity. However, links between service quality and productivity are more blurred. Contrary to the contention that co-production at the point of service interaction will increase the level of output as it enhances the user-organisation link, this is not universally proven. Even where there is an element of concurrency, the two elements of service work, the production of the service by the workforce and the consumption of the service by the public, may be focused in different directions. One element may potentially act as a brake on the other. Studies in the NHS in the early 2000s found no correlation between the star ratings of hospital performance and employee productivity (O'Mahony et al., 2009). The second issue is a related one. If productivity is seen to fall, the pressures on government will be to address these reductions in output. The tendency may be to scale down, abandon or adapt elements of the lean organisation to concentrate on worker output. Elements of lean working have previously been prone to pruning in post-lean implementation periods as the benefits become more difficult to justify.

The increased use of productivity targets presents particular challenges to the notion of co-production. While quality targets are ostensibly accessible to the service user (for example, the length of time for a hospital consultation or university student retention rates), productivity targets are largely hidden from the public. A patient or a student may attempt to co-produce a quality target, but the amount of effort expended in achieving a productivity target is unlikely to be of direct interest to the service user. More importantly, the productivity targets reflect a management-employer relationship divorced from the service user. Productivity targets which are increasingly foundational to lean working are created by public sector organisations to fit the financial resources available. Productivity targets are applied by management often in the face of the desire of state employees to provide better service to the public. The productivity targets do little other than create the illusion of coproduction. The emphasis on these types of performance targets promotes a myth of lazy public servants failing to exert sufficient effort in the interests of public good thereby placing their own interests above those of public service users and a government acting in the citizen's interest to eliminate waste from the public purse. The tenor of the government's Red Tape challenge (National Archives, 2016) was symptomatic of promoting the idea of user engagement in public services under the guise of collaboration between the state and citizens to remove unnecessary bureaucratic procedures. In reality, at the level of the workplace, productivity targets remain beyond the scope and influence of the citizen. Hood's first scenario is likely to reduce the capacity for co-production within a lean environment. The lean workplaces where productivity targets are currently central do not bode well should the state begin to shift away from administrative targets. Work intensification for the workforce and the exclusion of service users from influencing the processes of governance seem likely.

Hood suggests that the second major direction for public sector organisations in a cold fiscal climate is system redesign. There are two elements to this. The first at the level of citizen-government interaction may introduce an almost obligatory form of co-production where citizens are expected to contribute to the service formerly wholly provided by the state. Examples include the trend towards the self-assessment of personal taxation, householders sorting out domestic waste prior to collection and increased responsibility on the citizen to use predictive medical techniques. The user potentially gains a significant voice in determining what services will 
be offered and setting the costs. The second facet is a redesign of the incentive structures for cost containment with the aim of creating more pressure on public service organisations to limit costs. The latter facet, Hood suggests, is more prone to pressures exercised by some collective interests who may have a vested interest in the reduction of taxation.

On one level, lean working would appear to have the potential for greater congruence with service redesign. The service user is placed firmly at the centre of the production and consumption of the service. Rather than trying to amend an existing system of administration where the best that can be expected is addressing superficial issues while leaving more fundamental matters undisturbed (Radnor and Johnston, 2013), service redesign appears to provide a more radical root and branch approach to organisational change. Not only does it move the focus away from the internal workings of the organisation, it shifts it more fully on to the local users. Citizens determine the service and the cost they are willing to pay for it.

There are several difficulties for lean within the service redesign scenario particularly where coproduction is concerned. The differences between the delivery of transactional services and those more reliant on close interactions are again significant. Service redesign for transactional interactions between users and producers will be qualitatively different to those where personal interactions are central. There is little scope for coproduction in an area such as tax processing where exchanges between tax payers and HMRC are intermittent and impersonal. Unlike welfare or medical services where interactions are more continuous, there is little incentive for citizens to invest energy or interest in co-creating the redesign of tax services. Pestoff (2009) highlights that some state services encourage participation in the co-production process through the non-material rewards that citizens gain from their engagement. However, the requirement to complete a tax return is based primarily on the sanctions that the state can use to enforce compliance rather than the generation of social capital. There is an irony between recent government pronouncements and the ways in which lean is often implemented. The Open Public Services White Paper (HM Government, 2011), premised on decentralisation and allowing public servants the capacity to 'rip up the rule book', sits uneasily with lean whose implementation has relied on a standardised approach to the processing of work. The 'rule book' of state bureaucracy could in effect be replaced by the 'rule book' of lean processes. The lean approach is also arguably inconsistent with successful examples of coproduction where a standardised approach to service delivery may of itself be a barrier to a service responsive to client needs (Needham, 2006).

Although the state has rigorously followed a marketised approach to the delivery of public service, coproduction in service redesign retains distinctive elements that distinguish it from the private sector. The ongoing attempts by the state to maintain a 'customer focus' for each of its services may in effect treat organizational restructuring as a business process. However, this neglects that the citizen-state interaction is already inherently central to society. Interactions in part reflect the level of compliance that citizens need to give for the efficient organisation of society, but also that in receiving public services, users are both citizens (receiving public value from the state) and customers (receiving private value from state services) (Alford, 2002). A 'business' model such as lean takes the logic of the market and neglects the different bases on which user and provider interact. Coproduction appears to work more successfully, both in the UK as in Europe, where it is based on interdependence between citizens and service providers on a relational basis. With lean premised on standardised approaches and largely based on cost containment measures imposed by senior managers, this presents considerable challenges for co-creation of services. Variations in service delivery sit uneasily with a lean approach particularly where service providers are operating at a face to face level with users who may be unaware of the pressures on the providers to operate to certain formal standards (Needham, 2006).

\section{What's next?}

Lean, never a static beast, is likely to change and to develop as the state's intentions for the public sector become apparent. This final section of the article will outline a number of challenges for the future of organisational restructuring in the state sector.

The first challenge for state organisations is to take stock of the effectiveness of lean working within the public sector. Despite numerous iterations, lean successes have been limited in scope. There is a temptation to attribute failings in implementation to unreformed or poorly adapted versions of lean working taken uncritically 
from either the manufacturing sector specifically or from the private sector more generally. The casual observer might reasonably expect a greater degree of success for lean implementation taking into account the amount of energy expended on it. It might lead the observer to believe that lean is either of such complexity that it cannot be readily implemented or the public sector has had the misfortune to have a cohort of particularly inept managers, many of whom have failed to grasped the lean concept. However, neither explanation is wholly credible. The explanation lies closer to the political drivers that prompted the state sector's adoption of lean in the first place. With the state premising its funding of the public sector on cost containment, whichever business improvement is used, the technique of choice is largely adapted to fit the current marketised environment. The trend towards productivity targets of the type suggested by Hood's first scenario in combination with lean working is likely to lead to more working practices based around cost containment and treating the public as a 'target' to be met. Even with good intentions of supportive managers, lean is integral, not incidental, to public service restructuring. Put bluntly, there is a significant case for curtailing lean. As the state attempts to reduce its involvement in the public sector, lean techniques are likely to be used as a cost containment tool. Attempts to modify or ameliorate its implementation opens the door to its use as a further means to identify more efficiency savings.

The second challenge is to make the case for the re-evaluation of the strengths of the public sector model of work. More traditional models have potential for re-adaption for the current era. The main accusation against the traditional public sector model, often reflected in government policy, focuses on its rigidity and its inability to respond to user need. However, whereas business improvement approaches derived from the private sector promise greater economic efficiencies, the public sector model may ultimately be more efficient in the longer term (Du Gay, 2000). The economic benefits of a bureaucratic model are manifested in terms of public probity, consistency of approach and a public service ethos. Notwithstanding that a 'golden age' of public administration has never really existed, there is a risk in assuming that the problems that lean has recently sought to address are due to inefficiencies derived from traditional models of public administration. Public sector organisations have been overlaid with numerous attempts at restructuring. Hence, lean is as likely to be addressing residual elements of earlier re-organisations. A public sector ethos has potential to generate improvement in service even if these are of the 'common sense' variety (Moraros et al., 2016). Arguably many of the successes of co-production derive their strength from the public sector ethos of state employees. Despite a rhetoric of freeing state employees from the burden of bureaucracy, in practice state agencies are inundated with process-driven targets that arguably add little to the quality of the service provided.

The final challenge is that co-production needs to be considered in the context of collective interests. Successful examples of co-production reflect the advantages of a collective approach where a range of stakeholders are engaged with the process (Needham, 2006). Particularly where the interaction between state employee and service user is transactional and intermittent, the focus is on the value that the individual service user seeks to gain from a specific interaction. In collective approaches to co-production, the focus is on a diagnostic approach between users and providers. There is clearly a challenge to state organisations how they expand co-production to the intermittent interaction found, for example, in tax or social security assessment. Even where collective voices are heard, currently there are two aspects to the way that state agencies manage their organisations. The first is that although government policy promotes a narrative of decentralisation to allow civic society to shape public services, the reality is that state agencies are likely to centralise power within its management structures. This is because the financial restrictions placed on them by the cold fiscal climate limits freedom of action in line with budgetary restrictions. In tandem with this, the types of productivity target discussed above become the driving force. Where lean becomes a Trojan horse by which productivity targets are used to introduce further budgetary constraints, further centralisation is likely. The second aspect is the way in which the collective voice of the workforce is neglected or missing. Organisations often present lean to its workforce on the presumption that the qualities of lean working should be self-evidently worthy to anyone using it, thereby neglecting the benefits of customary ways of working (Waring and Bishop, 2010). Effective public administration requires a broader focus on collective interests, including the recognition of the need for dissenting voices to the use of private sector business models. The inclusion of the voice of the workforce would enhance the process of service improvement: open and honest interaction between service users and state employees would create a space for stakeholders to contribute to the improvement of state services. Without space for the contribution of the workforce, the risk is that co-production will focus on the achievement of targets rather than the process of reaching these outcomes. The inclusion of 
employees, even dissenting ones, provides opportunity to raise the profile of the process by which outcomes are reached. These process interactions are largely hidden from the public and potentially misunderstood. However current versions of lean often give little scope to much other than the achievement of performance targets with the 'customer' a process to be managed.

These three challenges sit uneasily with much current thinking of lean. However, as the UK continues to operate in an increasingly cold fiscal climate, it is an opportune moment to take stock. With lean acting as a means for public sector organisations to engage in cost containment, different routes are worth exploring before the state sector is damaged beyond repair.

\section{References}

Alford, J. (2002), Defining the client in the public sector: a social-exchange perspective. Public Administration Review, 62, 3, pp.337-446.

Bach, S. and Kessler, I., (2012), The Modernisation of Public Services and Employee Relations: Targeted Change (Palgrave Macmillan).

Bovaird, T. (2007), Beyond engagement and participation: user and community coproduction of public services. Public Administration Review, 67, 5, pp.846-860.

Bovaird, T. and Russell, K. (2007), Civil Service reform in the UK, 1999-2005: revolutionary failure or evolutionary success? Public Administration Review, 85, 2, pp.301-328.

Brandsen, T. and Honingh, M. (2016), Distinguishing different types of coproduction: a conceptual analysis based on the classical definitions. Public Administration Review, 75, 3, pp.427-435.

Carter, B., Danford, A., Howcroft, D., Richardson, H., Smith, A. and Taylor, P. (2011a), Lean and mean in the civil service: the case of processing in HMRC. Public Money \& Management, 31, 2, pp.115-122.

Carter, B., Danford, A., Howcroft, D., Richardson, H., Smith, A. and Taylor, P. (2011b), 'All they lack is a chain': lean and the new performance management in the British civil service. New Technology, Work and Employment, 26, 2, pp.83-97.

Diefenbach, T. (2009), New Public Management in public sector organizations: the dark side of managerialistic 'enlightenment'. Public Administration, 87, 4, pp.892-909.

Du Gay, P. (2000), In Praise of Bureaucracy: Weber, Organization, Ethics (Sage).

Esain, A., Williams, S. and Massey, L. (2008), Combining planned and emergent change in a healthcare lean transformation. Public Money \& Management, 28, 1, pp. 21-26.

Gershon, P. (2004), Releasing resources to the front line: independent review of public sector efficiency (The Stationery Office).

HM Government (2011), Open Public Services White Pape, (Crown Copyright).

Fillingham, D. (2007), Can lean saves lives? Leadership in Health Service, 20, 4, pp.231-241.

Hood, C. (2013), Reflections on public service reform in a cold fiscal climate. In Griffiths, S., Kippin, H. and Stoker, G. (eds.), Public Services: A New Reform Agenda (Bloomsbury), pp.215-229.

Moraros, J., Lemstra, M. and Nwankwo, C. (2016), Lean interventions in healthcare: do they actually work? A systematic literature review. International Journal for Quality in Health Care, 28, 2, pp.150-165.

National Archives (2016), Red tape challenge, viewed 16/02/2017 http://webarchive.nationalarchives.gov.uk/20150522175321/http:/www.redtapechallenge.cabinetoffice.gov.uk/hom e/index/. 
National Audit Office (2011), PaceSetter: HMRC's programme to improve business operations (NAO).

Needham, C. (2007), Realising the potential of co-production: negotiating improvements in public services. Social Policy and Society, 7, 2, pp.221-231.

O'Mahony, M., Stevens, P. and Stokes, L. (2009), Missing the target: can current measures of performance in the NHS be improved? (ESRC Public Services Programme), viewed 17/08/2016 http://www.publicservices.ac.uk/index.php/research/metrics-targets-and-performance.

Osborne, S., Radnor, Z. and Nasi, G. (2012), A new theory for public service management? Towards a (public) service-dominant approach. American Review of Public Administration, 43, 2, pp.135-158.

Pestoff, V. (2006), Citizens and co-production of welfare services. Public Management Review, 8, 4, pp.503-519.

Radnor, Z. and Johnston, R. (2013), Lean in UK government: internal efficiency or customer service? Production Planning and Control, 24, 10-11, pp.903-915.

Radnor, Z. and Osborne, S. (2013), Lean: a failed theory for public services? Public Management Review, 15, 2, pp.265-287.

Waring, J. and Bishop, S. (2010), Lean healthcare: rhetoric, ritual and resistance. Social Science and Medicine, 71, 7, pp.1332-1340

Public services have been implementing lean approaches with varying degrees of success. Lean is increasingly being used as a method of cost control rather than focusing on the requirements of public service users. Public sector organisations need to assess the respective value of productivity and quality targets used in lean working and the impact of targets on service delivery. Organisations also need to re-evaluate service redesign to ensure that lean is not hindering the co-creation of services. Public sector management has neglected the contribution of the workforce in reshaping public services to the detriment of public service users. 